\title{
Progression of Murine Lupus Nephritis Is Linked to Acquired Renal Dnase1 Deficiency and Not to Up-Regulated Apoptosis
}

\author{
Natalya Seredkina, Svetlana N. Zykova, \\ and Ole P. Rekvig \\ From the Molecular Immunology Research Group, Department of \\ Biochemistry, Institute of Medical Biology, Medical Faculty, \\ University of Tromsø, Tromsø, Norway
}

The accumulation of apoptotic cells has been suggested as a possible mechanism of nucleosome conversion into self-antigens that may both initiate autoimmune responses and participate in immune complex deposition in lupus nephritis. In this study, we analyzed both the rate of transcription of apoptosis-related genes and the presence of activated apoptotic factors within kidneys of lupus-prone $(\mathrm{NZB} \times \mathrm{NZW}) \mathrm{F} 1$ mice during disease progression. The results of this study demonstrated no activation of apoptotic pathways in kidneys of these lupus-prone mice at the time of appearance of anti-double standard DNA antibodies in serum, as well as the formation of mesangial immune deposits in glomeruli. In contrast, the transition of mesangial into membranoproliferative lupus nephritis coincided with an accumulation of activated caspase 3-positive cells in kidneys, in addition to a dramatic decrease in Dnase1 gene transcription. Highly reduced expression levels of the Dnase1 gene may be responsible for the accumulation of large chromatin-containing immune complexes in glomerular capillary membranes. Thus, the initiation of lupus nephritis is not linked to increased apoptotic activity in kidneys. The combined down-regulation of Dnase 1 and the increased number of apoptotic cells, which is possibly due to their reduced clearance in affected kidneys, may together be responsible for the transformation of mild mesangial lupus nephritis into severe membranoproliferative, end-stage organ disease. (Am J Pathol 2009, 175:97-106; DOI: 10.2353/ajpath.2009.080943)

Affection of kidneys is a major complication in systemic lupus erythematosus and lupus nephritis is associated with high rate of morbidity and mortality. According to the
International Society of Nephrology/Renal Pathology Society classification criteria it is separated into six different classes from subclinical (class I) to end-stage disease (class VI). ${ }^{1}$

Nucleosomes play a central role as potential inducers of autoantibody production and in formation of immune complexes. ${ }^{2-7}$ They are normal products of apoptosis, but it is still not clear how intracellular self-antigens like nucleosomes become immunogens capable of triggering and maintaining a strong and prolonged autoantibody production..$^{8,9}$ One hypothesis indicates that a dysregulation of apoptosis might be responsible for transformation of apoptotic into secondary necrotic chromatin. Such necrotic chromatin may potentially induce cellular and humoral autoimmunity and particularly antibody production to double-stranded DNA (dsDNA) and nucleosomes. ${ }^{10-13}$ Most discussions concentrate on increased apoptotic activity and accumulation of apoptotic, secondary necrotic cells due to reduced clearance of the dead cells as central events in the evolution of lupus nephritis. Increased apoptotic activity among peripheral blood cells from systemic lupus erythematosus patients ${ }^{14-16}$ and its positive correlation with autoantibody production and disease activity has been reported. ${ }^{17}$ Recent studies suggest the same for glomerular cell apoptosis in human and murine lupus nephritis. ${ }^{5,18}$ Such results are based on detection of apoptotic cells, whereas expression of apoptotic triggers and executioners has not been subjected to detailed investigations so far in lupus nephritis. Many studies have demonstrated impaired clearance of apoptotic cells in systemic lupus erythematosus. ${ }^{19-21}$ This may result in accumulation of apoptotic cells without prior rise in the rate of apoptosis.

Supported by Foundation for Health and Rehabilitation through the Norwegian Rheumatology Organization (2004/2/0250), from Northern Norway Regional Health Authority Medical Research Program (SFP-100-04, SFP101-04, and Thematic Research Support), and from University of Troms $\varnothing$ as a Milieu support given to O.P.R.

Accepted for publication April 9, 2009.

Address reprint requests to Ole Petter Rekvig, Molecular Immunology Research group, Department of Biochemistry, Institute of Medical Biology, University of Tromsø, N-9037 Tromsø, Norway. E-mail: olepr@fagmed.uit.no. 
Therefore, to determine whether there is an increase in the apoptotic activity in systemic lupus erythematosus, or whether accumulation of apoptotic or secondary necrotic debris may be due to reduced clearance, the apoptotic pathways need to be investigated.

The extrinsic apoptotic pathway is initiated through the ligation of specific death receptors on the cell surface, which is followed by a cascade of enzymatic activations and identifiable morphological changes in cells and particularly in nuclei. Signaling is provided through the extrinsic pathway from receptors (Fas, tumor necrosis factor receptor superfamily, member 1a) toward activation of caspases through involvement of adaptor proteins Fas (TNFRSF6)-associated via death domain, TNFRSF1A-associated via death domain) that form bridges between downstream regulators and effectors. ${ }^{22}$ Anti-apoptotic (Bcl2l2) and pro-apoptotic (BCL2-associated X protein) members of the $\mathrm{Bcl}-2$ protein family play a key role in controlling execution of the intrinsic apoptotic pathway. ${ }^{23}$ Thus, investigation of apoptotic processes needs an integrated assessment of apoptotic triggers, executioners and effectors.

In this study, we analyzed whether there is an upregulated apoptotic activity in kidneys of lupus-prone BW mice during nephritis progression since accumulation of apoptotic cells is an obligate observation during development of lupus nephritis. ${ }^{5,18}$ We also analyzed whether accumulation of chromatin fragments in glomerular capillary membranes and mesangial matrix relates to reduced fragmentation of apoptotic chromatin by diminished transcription of the renal Dnase1 gene, and secondary to this, decreased clearance of large chromatin fragments.

\section{Materials and Methods}

\section{Animals}

Female (NZBxNZW)F1 (BW) and BALB/c mice were purchased from Harlan (Blackthorn, UK), while MRL-Ipr/lpr mice were purchased from Jackson Laboratory (Bar Harbor, Maine). Treatment and care of animals were in accordance with the guidelines of The Norwegian Ethical and Welfare Board for Research Animals, and the study was approved by the Institutional Review Board.

\section{Induction of Proteinuria in BALB/c Mice by Injecting Highly Pure Murine Anti-dsDNA Monoclonal Antibodies (mAbs)}

Healthy 10 -week-old BALB/c mice $(n=3)$ where injected twice a week for 4 weeks with $200 \mu \mathrm{g}$ purified murine anti-dsDNA mAbs (DNA6 mAb, kindly provided by $T$ Marion, Memphis, TN) each time, similar to protocols used by others. ${ }^{24,25}$ These were purified according to the protocol III of Kramers et al, ${ }^{25}$ and were shown to contain only IgG heavy and light chains, and not DNA or histone proteins (data not shown). Granular deposits of chromatin-IgG complexes appeared in glomeruli at end-point in the injected mice (data not shown), and severe proteinuria developed progressively in these mice to levels com- parable with those in BW and MRL-Ipr/lpr mice with endstage organ disease.

\section{Collection of Samples from Mice}

Serum samples from BW and sex-, age-matched BALB/C mice were collected from 4-, 8-, or 20-week-old (group 1, 2 , and 3 respectively) and at the time of full-blown nephritis (group 4, mice $\geq 26$ weeks old), while sera from MRL-Ipr/lpr and BALB/c mice injected with anti-dsDNA mAbs were collected at end-point when mice suffered from severe proteinuria. Sera were stored at $-20^{\circ} \mathrm{C}$. Proteinuria was monitored weekly with sticks from Bayer Diagnostics (Bridgend, UK). At the age of 4, 8, 20 weeks, or after indication of severe nephritis (proteinuria $\geq 3 \mathrm{~g} / \mathrm{L}$ ), animals were euthanized by $\mathrm{CO}_{2}$-suffocation. Each group contained 5 to 6 animals. Kidneys were extirpated, cut, and fixed in RNAlater (Qiagen Nordic, Norway) for further analysis of gene transcription, or fixed in $4 \%$ buffered depolymerized paraformaldehyde and embedded in paraffin for immunohistochemical analysis, or fixed in $8 \%$ buffered depolymerized paraformaldehyde for electron microscopy. The same samples were collected from sexand age-matched BALB/c control mice. MRL-Ipr/lpr mice and BALB/c mice injected with anti-dsDNA mAbs were used as proteinuric control mice to analyze if proteinuria per se affected renal gene transcription and apoptotic activities in BW mice. Samples from MRL-Ipr/lpr mice were collected at age of 4 weeks and at severe nephritis. Injected BALB/c mice with proteinuria and age-matched non-treated BALB/c mice were euthanized at 14 weeks of age. Control groups included three animals in each. Organs from those animals were collected in the same way as from BW mice.

\section{Anti-dsDNA Enzyme-Linked Immunosorbent Assay}

Calf thymus dsDNA and Sigma fast orthophenylendiamine substrate were purchased from Sigma-Aldrich (St. Louis, MO). Murine serum antibodies against calf thymus dsDNA were detected and titrated by standard indirect enzyme-linked immunosorbent assay, as described in detail. ${ }^{26}$

\section{Colocalization Immune Electron Microscopy}

Immune electron microscopy was performed on murine kidney sections as previously described. ${ }^{5}$ Sections were incubated with rabbit anti-mouse IgG (RaM IgG, Cappel, ICN Pharmaceuticals, Inc.) and protein A conjugated with 5-nm gold particles (PAG-5 nm, University of Utrecht, The Netherlands) followed by fixation with glutaraldehyde and saturation of free aldehyde groups by glycine. In a next step, the same sections were incubated with the antidsDNA mAb DNA6 and protein A conjugated with 10-nm gold particles (PAG-10 nm) to determine whether in vivobound autoantibodies co-localized with DNA6 in extracel- 
lular chromatin. Micrographs were taken using a Jeol JEM1010 Transmission Electron Microscope (Tokyo, Japan).

\section{Immunohistochemical Analysis}

Apoptotic factors in kidneys of the mice included in this study were detected by using Envision+Dual Link System-HRP (diaminobenzidine+) (Dako Norden A/S, Denmark). After deparaffinization of 4- $\mu \mathrm{m}$ paraffin-embedded kidneys sections, they were heated in citrate buffer, pH 6.0, for 20 minutes at $98^{\circ} \mathrm{C}$, then blocked with peroxide for 5 minutes, followed by 60 minutes incubation with blocking solution (0.2\% Triton $\mathrm{X}-100,2 \%$ goat serum, lamb serum, fetal calf serum, and $2 \%$ bovine serum albumin) to prevent non-specific antibody binding. Subsequently, sections were incubated for 30 minutes with primary antibody to stain for activated caspase 3 (rabbit anti-mouse active caspase 3 antibody diluted 1:500, R\&D Systems, Abinodon, UK), activated caspase 9 (rabbit anti-mouse activated caspase 9 antibody 1:2000, Nordic Biosite AB, Sweden), apoptotic peptidase activating factor 1 (rabbit anti-mouse APAF1 antibody 1:75, Acris Antibodies $\mathrm{GmbH}$, Germany) or negative controls (normal rabbit IgG at the same concentration as primary antibodies, R\&D Systems, Abinodon, UK). Secondary antibody and diaminobenzidine chromogen solution were used according to instruction from Dako. Sections were counterstained with hematoxylin and Scott's solution. To evaluate the number of positively stained cells we counted them in 10 view fields $($ magnification $=$ original $\times 20)$ per kidney section.

\section{Gene Expression Analysis}

Total RNA was isolated with EZ-1 RNA tissue mini kit (Qiagen). The quality of RNA was analyzed by Agilent Bioanalyzer using RNA 6000 assay kit (Agilent Technologies, Inc., CA). cDNA was transcribed from RNA by using cDNA Archive kit (Applied Biosystems, CA). For real time PCR we used TaqMan Gene Expression Assays (Applied Biosystems, CA): tumor necrosis factor (TNF)- $\alpha$ Mm00443258_m1; FAS receptor Mm00433237_m1; TNFR I Mm00441875_m1; TNFR || Mm00441889_m1; TRAF2 Mm00801978_m1; FADD Mm00438861_ m1; TRADD Mm01251029_m1, Bcl2l2 Mm00432054_m1; BAX Mm00432050_m1; Cytochrome C somatic Mm01621044_g1; APAF1 Mm00437530_m1; caspase 9 Mm00516563_m1; caspase 3 Mm01195085_m1; Dnase $1 \mathrm{Mm01342389}$ g1; endogenous control - Mouse actin $\beta$ 4352933E, and TATA binding protein Mm00446973_m1. The assays were performed on ABI Prism $7900 \mathrm{HT}$ Sequence Detection System (Applied Biosystems). Expression levels were calculated using the ddCT method. Data are given as fold change compared with transcription in 4-week-old mice.

\section{Camptothecin-Induced Apoptosis in Isolated Kidneys}

Mice were euthanized by $\mathrm{CO}_{2}$ and kidneys were immediately extirpated and placed into 24 well plates (half a kidney per well) with apoptosis inducing solution $-5 \mu \mathrm{mol} / \mathrm{L}$ camptothecin (Sigma-Aldrich, St Louis, MO) in RPMI-1640 with $10 \%$ fetal calf serum. The kidneys were incubated for 0 , 2,4 , or 6 hours at $37^{\circ} \mathrm{C}$ in $5 \% \mathrm{CO}_{2}$, then cut and fixed in $4 \%$ buffered depolymerized paraformaldehyde for morphological studies or in RNAlater (Qiagen) for further analyses of gene transcription. DNA fragmentation was determined by Agilent bioanalyzer as described before. ${ }^{27}$

\section{Statistical Analysis}

Two-way analysis of variance was used to compare the Ct values between the age groups and the strains in the gene expression study. Differences were regarded significant at $P<0.05$ provided at least twofold changes of mRNA levels. One-way analysis of variance with Dunett post hoc test was used to assess the differences in the number of active caspase-3-positive cells on the sections of kidneys with various degrees of morphological changes.

\section{Results}

\section{Analyses of Serum Antibodies against dsDNA and Renal Morphology in BALB/C and BW Mice}

The four age groups of BW mice were analyzed for appearance of circulatory anti-dsDNA antibodies and for morphological changes in glomeruli. Figure $1 \mathrm{~A}$ demonstrate serum levels of anti-dsDNA antibodies in each group of $\mathrm{BW}$ mice (results given as mean $\mathrm{OD}_{490} \pm$ SEM for each group). Sex and age matched BALB/c mice were negative for anti-dsDNA antibodies (data not shown).

Four- and 8-week-old BALB/c or BW mice had normal kidney morphology and no serum anti-dsDNA antibodies. Immune electron microscopy analysis did not show any immune complex deposits, nor electron dense structures in glomeruli of groups 1-3 BW mice (data not shown). Group 3 mice had low levels of anti-dsDNA autoantibodies (Figure 1A).

The nephritic group 4 mice (age $\geq 26$ weeks old, $n=6$ ) with high levels of anti-dsDNA antibodies (Figure 1A) was divided into two subgroups due to distinctly different morphological patterns observed by immune electron microscopy, three animals in each. Group 4A had granular deposits of IgG in the mesangial matrix only (Figure $1 \mathrm{~B}$ ), while group $4 \mathrm{~B}$ demonstrated massive deposition of IgG associated with EDS in glomerular capillary membranes (Figure 1C). Glomerular in vivo-bound IgG were strictly associated with EDS in group 4A and group 4B mice as demonstrated by immune electron microscopy. Furthermore, these in vivo-bound IgG molecules (traced by 5 -nm gold particles) co-localized with anti-dsDNA mAb DNA6 added to the sections in vitro (traced by 10-nm gold particles), indicating presence of immune complexes consisting of $\operatorname{lgG}$ and chromatin fragments (see Figure 1, B and C, for details). 


\section{A Serum anti-dsDNA autoantibodies}
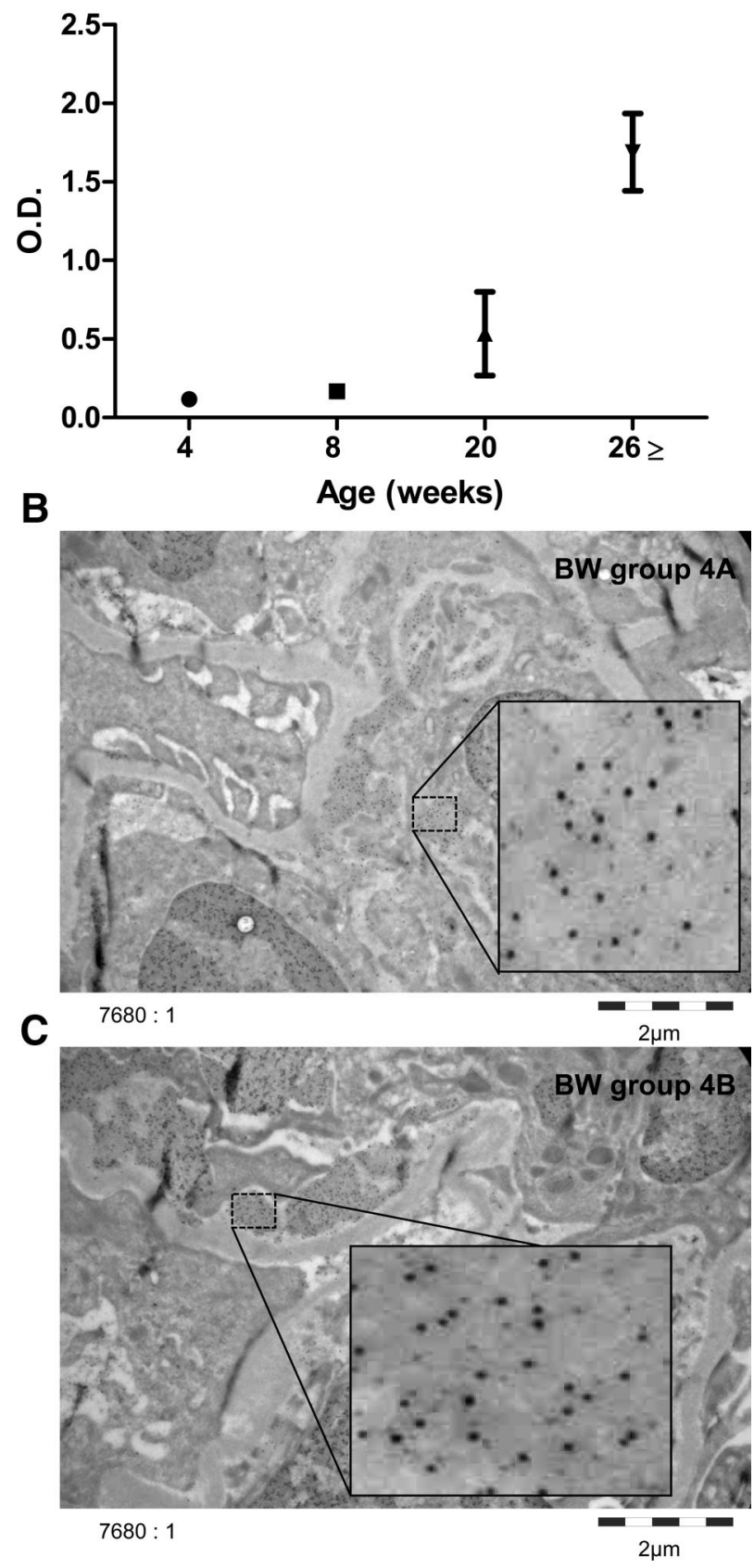

Figure 1. Levels of serum anti-dsDNA autoantibodies in BW mice of different ages and immune electron microscopic detection of chromatin-IgG complex deposition in glomeruli of mice with different stages of lupus nephritis. Murine serum antibodies against calf thymus dsDNA were analyzed at end point by indirect enzyme-linked immunosorbent assay in each group of $\mathrm{BALB} / \mathrm{c}$ (data not shown) and BW mice (A). Data are given as mean $\mathrm{OD}_{490} \pm$ SEM at serum dilution $1 / 100$ for each group. Group $1-3$ consisted of five mice. BW mice with nephritis consisted of six mice and were divided into two subgroups each consisting of three mice; group $4 \mathrm{~A}-$ mice with immune complexes located only in mesangium (B); group $4 \mathrm{~B}-$ mice with massive chromatin deposition in glomerular capillary membranes observed as electron dense structures $(\mathbf{C})$. Presence of chromatin in membranes is traced by $10 \mathrm{~nm}$ gold (larger dark particles), whereas in vivo-bound IgG is traced by 5 -nm gold (smaller light gray particles). Co-localization of 10- and 5-nm gold particles demonstrates that chromatin and in vivo-bound IgG is contained in glomerular membrane-associated electron dense structures.

\section{Immunohistochemical Detection of Apoptotic} Cells in Kidneys

To determine the amount of apoptotic cells in kidneys we stained tissue sections with antibodies against several apoptotic proteins. Activated caspase 3 and 9 and APAF1 were chosen as reliable indicators for presence of apoptotic cells compared with the use of for example, the terminal deoxynucleotidyl transferase dUTP nick-end labeling assay. ${ }^{28,29}$ These factors reflect activation of both the intrinsic and extrinsic apoptotic pathways.

Immunohistochemical analysis showed no difference between staining of activated caspase 3 and 9 or APAF 1 in kidneys from groups 1 (Figure $2, \mathrm{~A}-\mathrm{C}$, respectively), 2 and 3 (data not shown) of the BW mice compared with age-matched BALB/c mice.

Slightly increased number of active caspase 3-positive cells was found in kidneys of nephritic mice (Figure 2D), mostly located in tubuli and interstitial area (Figure 2D, arrows), and few apoptotic cells were observed in glomeruli. Interestingly, antibodies against activated caspase 3 and 9 and APAF 1 gave strong staining of structures in tubular lumina in nephritic kidneys (Figure 2, D (inset), E, and $F$, for activated caspase 3, caspase 9, and APAF 1 , respectively). No staining was found in tubular lumina in nephritic kidneys using nonspecific rabbit IgG (insert in Figure 2F). Other proteinuric kidneys, like those from severely proteinuric BALB/C mice injected with antidsDNA antibodies, did not contain caspase 3 and 9 and APAF 1 positive structures in their lumina (data not shown). These latter data argue against the idea that debris in tubular lumina is a non-specific result of proteinuria. When analyzing kidneys from severely nephritic MRL-Ipr/Ipr mice, which have a distinctly different genetic background for development of lupus-like nephritis, smaller and fewer apoptotic structures could be observed in tubular lumina compared with what was observed in the nephritic BW kidneys (data not shown).

The number of activated caspase 3-positive cells was determined in kidney sections of nephritic BW mice in comparison with younger BW and age matched BALB/C mice (Figure 3 right axis) and plotted against the absolute number of renal cells in the same slides (Figure 3 left axis). There was no significant difference in the number of activated caspase 3-positive cells between BALB/c kidneys from different age groups, while in group $4 \mathrm{~B}$ of $\mathrm{BW}$ mice the number of activated caspase 3-positive cells was significantly increased, as compared with young BW group 1 mice $(P<0.05)$. This rise did not correspond to elevation of absolute number of renal cells in the nephritic group. There was no significant difference in the number of activated caspase 3-positive cells in kidneys from nephritic BW mice compared with age-matched BALB/c mice. Subgroups $4 A$ and $4 B$ BALB/c mice were divided in compliance with age of group $4 A$ and $4 B$ BW mice. In control experiments, we observed that sections of kidneys from BALB/c mice with severe proteinuria after injection of anti-dsDNA mAbs had no more activated caspase 3-positive cells than young or age-matched non-treated BALB/c mice (Figure 4A). Similarly, in MRL- 
A

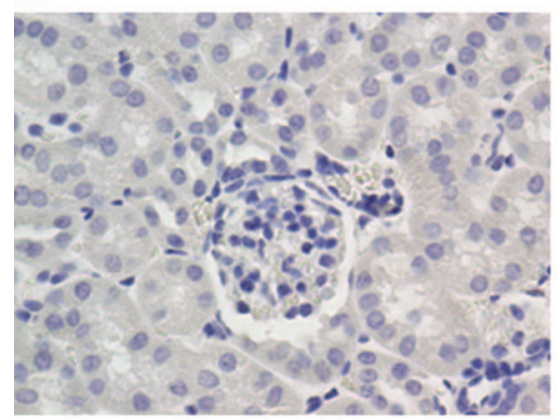

D

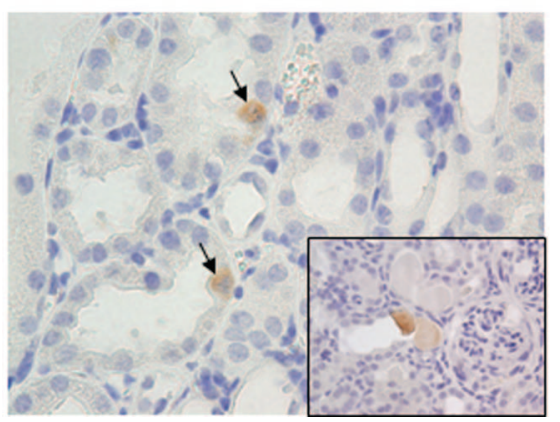

B

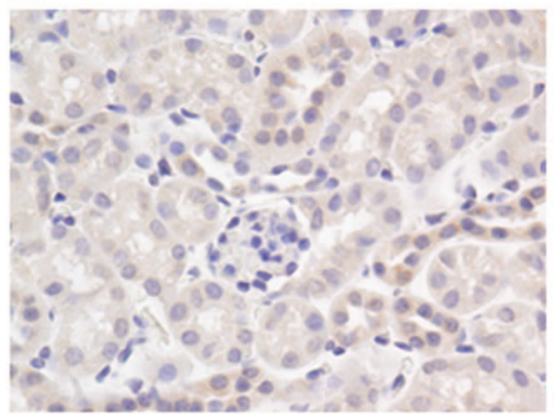

E

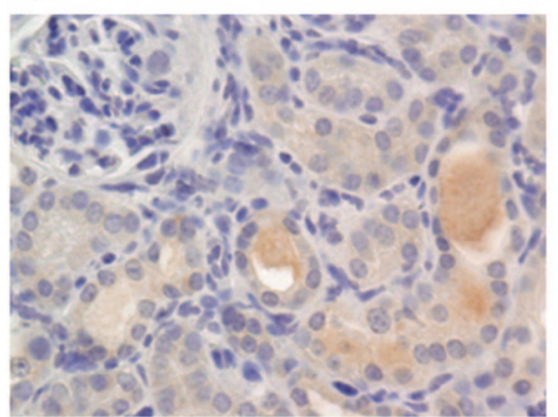

C

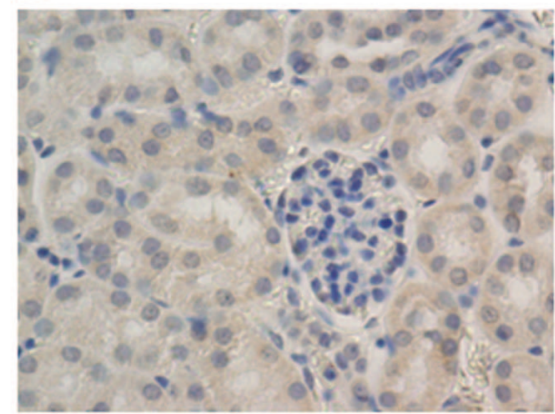

$\mathbf{F}$

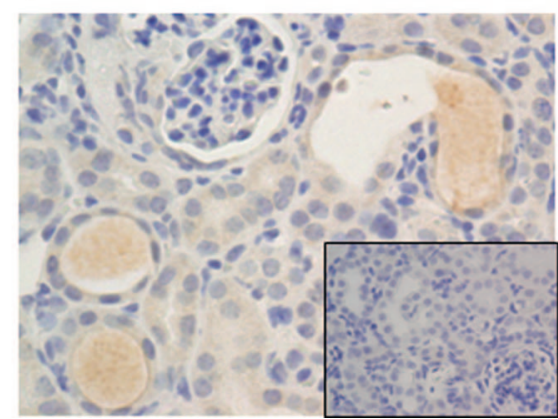

Figure 2. Detection of apoptotic factors in kidneys of young (A-C) and nephritic (D-F) BW mice. Data are demonstrated for activated caspase 3 (A, D), APAF1 $(\mathbf{B}, \mathbf{E})$ and activated caspase $9(\mathbf{C}, \mathbf{F})$ in kidneys from 4-week-old (upper panels) and nephritic (lower panels) BW mice. There is increased numbers of activated caspase 3-positive cells in tubular cells from proteinuric BW mice (D) and also activated caspase 3-positive structures in tubular lumina (inset in D), whereas no staining was observed in kidney sections from young BW mice (A). Activated caspase 9 and APAF 1 were absent in kidneys from young BW mice (B, C, for APAF1 and activated caspase 9, respectively), but gave strong staining in tubular lumina in the proteinuric kidneys (E, F, respectively). There was no staining in negative controls using non-specific rabbit IgG (inset in $\mathbf{F}$ ). Magnification $=$ original $\times 40$. Arrows in $\mathbf{D}$ point at activated caspase 3 -positive cells.

Ipr/lpr mice with severe nephritis, kidneys contained only slightly more activated caspase 3-positive cells than young animals of the same strain. The difference was, however, not statistically significant (Figure 4A), thus indicating that proteinuria did not cause increased apoptosis in these proteinuric mice.

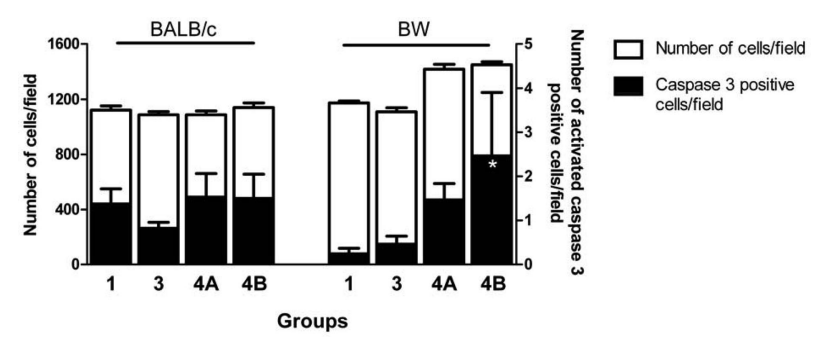

Figure 3. Quantitative analysis of activated caspase 3-positive cells in kidneys from BALB/c and BW mice. Activated caspase 3-positive cells were counted on the tissue sections (right axis) and plotted against the absolute number of renal cells in the same slides (left axis). Number of cells is given as average of 10 view fields per kidney section from all mice $(n=5$ for groups 1 and 3 , and $n=3$ for groups $4 \mathrm{~A}$ and $4 \mathrm{~B}$ ) of the different age groups. In BALB/c kidneys, the number of caspase 3-positive cells remained the same in all of the age groups, whereas in BW kidneys, there was a significant increase in group $4 \mathrm{~B}$, as compared with group 1. Asterisk in group $4 \mathrm{~B}$ indicates a significant increase in activated caspase 3-positive cells compared with group $1(P<0.05)$. BALB/c groups $4 \mathrm{~A}$ and $4 \mathrm{~B}$ corresponds to age of Group 4A (mesangial matrix deposits) and $4 \mathrm{~B}$ (capillary membrane deposits) nephritic BW mice.

\section{Renal Transcription of Central Apoptotic Genes in Different Age Groups of BW and Nontreated $B A L B / c$ Mice}

Increased numbers of apoptotic cells in the nephritic BW group 4B compared with groups 1-4A as detected by immunohistochemistry, could be due to impaired clearance of apoptotic cells or to increased apoptotic activity. We analyzed renal transcription of several apoptosisassociated genes, including transcription of genes encoding apoptosis inducers, receptors, pro- and anti-apoptotic regulators, caspases, and Dnase1. Real-time PCR was performed on kidney mRNA from BW (Table 1) and BALB/C mice (data not shown) in the different age groups. The differences were regarded significant at $P<$ 0.05 provided at least twofold changes of mRNA levels compared with results in BALB/c mice. The expression of all presented genes was stable without changes throughout the observation time in BALB/c kidneys (data not shown). Major changes in transcription were found for the TNF- $\alpha$, TNFR II, Cytochrome c somatic, and Dnase1 genes in the proteinuric BW group, as compared with healthy sex and age matched control BALB/C mice. Expression of those genes was also significantly changed in nephritic BW kidneys compared with kidneys from 4-week-old BW mice (Table 1). Interestingly, increase in expression of TNF- $\alpha$ and its receptor was not linked to changes in 

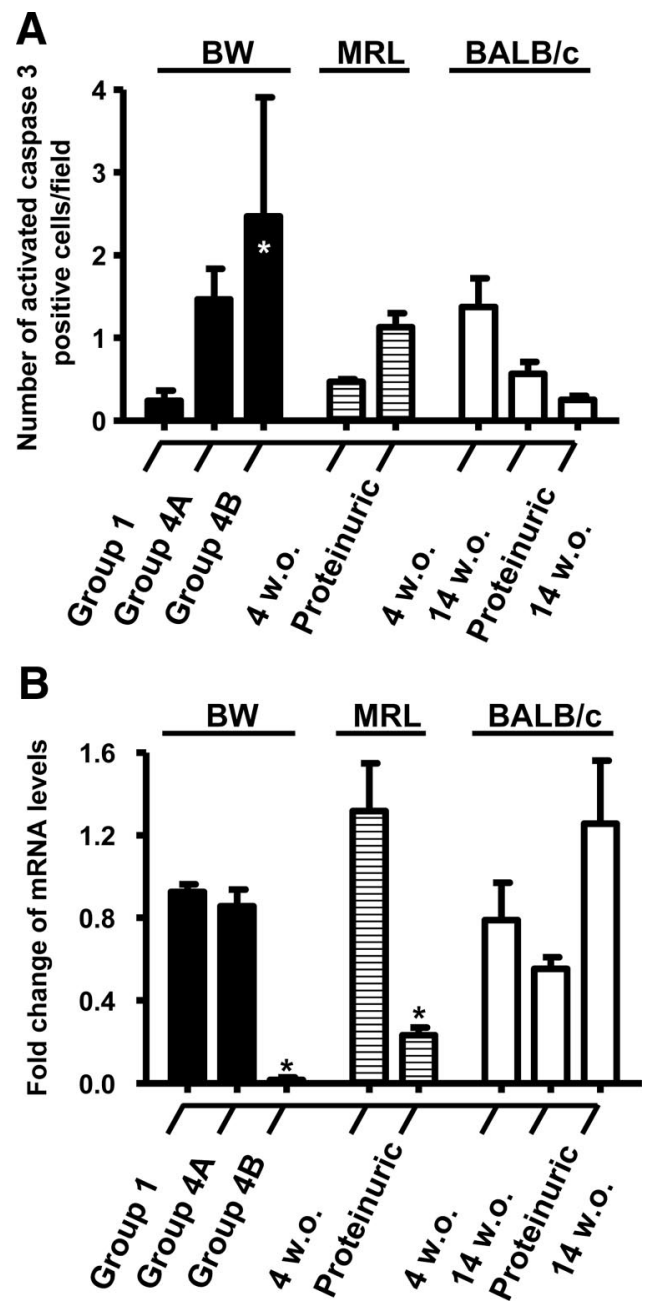

Figure 4. Number of activated caspase 3 positive cells and changes in Dnase $I$ gene expression in kidneys with proteinuria based on different etiologies. An averaged number of activated caspase 3-positive cells obtained by counting 10 view fields per kidney section from different groups of mice is presented. The bars represent mean of the groups ( \pm SEM; $n=5$ for group 1 of BW and $n=3$ for the rest of the groups) A: Data from proteinuric kidneys are presented in comparison with results from young animals of the same strain. For BALB/c mice data are given also from non-treated agematched animals. Significant increase in the number of activated caspase 3-positive cells was found only in group 4B (with large electron dense structures in capillary membranes) compared with group 1 of BW mice. Asterisk in group $4 \mathrm{~B}$ indicates a significant increase compared with group 1 $(P<0.05)$. Changes in Dnase I gene transcription are calculated individually for each strain against their corresponding controls (one 4 week old BW, MRL or BALB/c mice) B: Expression of Dnase I was stable in BALB/c kidneys even in mice with severe proteinuria, while it was significantly decreased in nephritic MRL-lpr/lpr kidneys and in kidneys from group 4B of nephritic BW mice. Asterisk indicates a significant decrease of Dnase I transcription (group $4 \mathrm{~B}$ of BW mice and the proteinuric group of MRL-lpr/lpr mice compared with young animals of the same strains, ${ }^{*} P<0.05$ ).

expression of caspase 3 or caspase 9 at the proteinuric stage.

Importantly, transcription of the Dnase 1 gene, coding for the major renal nuclease, ${ }^{30}$ was insignificantly reduced in proteinuric mice with mesangial deposits of EDS-IgG complexes only (Table 1, group 4A, and Figure 1B). In proteinuric BW mice with massive IgG-containing EDS in glomerular capillary membranes, Dnase1 gene transcription was substantially reduced (Table 1 , group $4 \mathrm{~B}$, Figure $1 \mathrm{C}$ ). This together with the recently published observation of the impaired ability to degrade chromatin in kidneys from lupus nephritis-prone BW mice ${ }^{27}$ and low Dnase1 enzyme activity in the nephritic BW kidneys (Zykova et al, manuscript submitted) suggests that poor processing of nuclear debris is linked to deposition of chromatin fragments in glomerular capillary membranes and development of a severe form of lupus nephritis.

To analyze if reduced Dnase 1 mRNA levels in nephritic kidneys is secondary to proteinuria, we measured Dnase 1 mRNA levels in group 1, group 4A and 4B of BW mice and compared with young and 14-week-old nonproteinuric and proteinuric BALB/c mice injected with anti-dsDNA mAbs. While Group 4B BW mice demonstrated profound down-regulation of Dnase 1 mRNA levels, this was not observed in BALB/c mice with severe proteinuria (Figure 4B). This demonstrates that proteinuria by itself does not promote down-regulation of the renal Dnase1 gene. Interestingly, in nephritic MRL-Ipr/lpr kidneys, the Dnase1 mRNA levels were low compared with kidneys from 4-week-old MRL-Ipr/lpr mice similar to the observed reduction in BW kidneys with membranoproliferative nephritis (Figure 4B). Taken together, these data demonstrate that proteinuria does not cause reduction in Dnase1 mRNA levels directly, while loss of renal Dnase 1 expression and activity (Zykova et al, manuscript submitted) seem to be linked to basic processes responsible for lupus nephritis that are operational in both BW and MRL-Ipr/lpr mice.

\section{DNA Fragmentation, and Expression of Apoptotic Factors and Dnase1 after Camptothecin-Induced Apoptosis in Isolated Nephritic BW Kidneys}

To test the ability of cells from BW kidneys to undergo apoptosis we induced apoptosis ex vivo by camptothecin in kidneys of non-nephritic 12-week-old BW and nephritic BW mice and age-matched non-proteinuric BALB/c control mice. After incubation of the kidney samples with camptothecin for 6 hours, multiples of 200-bp DNA fragments, typical of apoptosis, were observed in BALB/C kidneys, but not in kidneys from nephritic BW mice (Figure $5 \mathrm{~A}$ ). This result is consistent with the observation that transcription of the major renal nuclease Dnase 1 gene in nephritic kidneys was selectively low at all incubation periods with camptothecin (Figure 5B, Table 1) in contrast to young BW kidneys (Table 1), while in BALB/C kidneys Dnase1 transcription was higher and increased at 6 hours' incubation time (Figure 5B). Immunohistochemical analysis of activated caspase 3-positive cells showed increased numbers of positively stained cells in young (data not shown) and especially in nephritic BW kidneys compared with healthy controls after incubation with camptothecin for 6 hours (Figure 5, C and D). We also analyzed apoptotic gene expression in the course of camptothecin-induced cell death. There were no significant changes in transcription of apoptosis-associated genes in the BW kidneys compared with healthy control animals (data not shown). The reason for this result may 
Table 1. Transcriptional Activities of Central Apoptotic Genes in (NZBxNZW)F1 Mice

\begin{tabular}{|c|c|c|c|c|c|}
\hline \multirow[b]{3}{*}{ Genes } & \multicolumn{5}{|c|}{ Relative renal gene transcription levels* in groups of (NZBXNZW)F1 mice } \\
\hline & \multirow{2}{*}{$\begin{array}{l}4 \text { week old } \\
\text { Group } 1\end{array}$} & \multirow{2}{*}{$\begin{array}{l}8 \text { week old } \\
\text { Group } 2\end{array}$} & \multirow{2}{*}{$\begin{array}{l}20 \text { week old } \\
\text { Group } 3\end{array}$} & \multicolumn{2}{|c|}{$\geq 26$ weeks old ${ }^{\dagger}$} \\
\hline & & & & Group 4A & Group 4B \\
\hline$T N F-\alpha$ & $1.42 \pm 0.39$ & $1.27 \pm 0.31$ & $3.77 \pm 1.60^{\ddagger}$ & $19.59 \pm 9.10^{\ddagger}$ & $28.03 \pm 7.70^{\ddagger}$ \\
\hline TNFR I & $1.20 \pm 0.16$ & $0.93 \pm 0.10$ & $1.37 \pm 0.14$ & $1.56 \pm 0.24$ & $2.28 \pm 0.16$ \\
\hline TNFR // & $1.03 \pm 0.17$ & $1.00 \pm 0.19$ & $1.82 \pm 0.47$ & $3.46 \pm 2.45$ & $7.61 \pm 1.91^{\ddagger}$ \\
\hline FAS receptor & $0.79 \pm 0.10$ & $0.83 \pm 0.07$ & $1.18 \pm 0.13$ & $1.27 \pm 0.03$ & $1.20 \pm 0.09$ \\
\hline$F A D D$ & $0.84 \pm 0.22$ & $0.75 \pm 0.12$ & $1.23 \pm 0.30$ & $0.89 \pm 0.78$ & $0.93 \pm 0.13$ \\
\hline TRADD & $1.06 \pm 0.17$ & $0.82 \pm 0.20$ & $1.10 \pm 0.18$ & $1.46 \pm 0.3$ & $1.08 \pm 0.09$ \\
\hline TRAF2 & $0.91 \pm 0.15$ & $0.76 \pm 0.13$ & $0.94 \pm 0.16$ & $1.03 \pm 0.33$ & $1.63 \pm 0.16$ \\
\hline Bc/2/2 & $0.99 \pm 0.09$ & $0.87 \pm 0.15$ & $0.99 \pm 0.04$ & $0.81 \pm 0.46$ & $0.86 \pm 0.11$ \\
\hline$B A X$ & $1.28 \pm 0.09$ & $0.94 \pm 0.10$ & $1.12 \pm 0.14$ & $1.39 \pm 0.09$ & $1.71 \pm 0.14$ \\
\hline Cytochrome c s & $1.20 \pm 0.38$ & $1.57 \pm 0.38$ & $0.88 \pm 0.34$ & $0.59 \pm 0.07^{\ddagger}$ & $0.26 \pm 0.05^{\ddagger}$ \\
\hline APAF 1 & $1.33 \pm 0.09$ & $0.88 \pm 0.05$ & $1.16 \pm 0.17$ & $1.13 \pm 0.76$ & $2.55 \pm 0.25$ \\
\hline Caspase 9 & $0.69 \pm 0.08$ & $0.66 \pm 0.12$ & $1.15 \pm 0.08$ & $0.75 \pm 0.56$ & $1.05 \pm 0.2$ \\
\hline Caspase 3 & $1.19 \pm 0.10$ & $0.72 \pm 0.13$ & $0.98 \pm 0.14$ & $0.93 \pm 0.01$ & $1.14 \pm 0.15$ \\
\hline Dnase 1 & $0.84 \pm 0.12$ & $0.91 \pm 0.11$ & $1.15 \pm 0.24$ & $0.71 \pm 0.11$ & $0.02 \pm 0.02^{\ddagger}$ \\
\hline
\end{tabular}

Cytochrome c s, Cytochrome c somatic.

${ }^{*}$ Data are given as fold change compared with transcription in a 4-week-old BALB/c mouse. Values represent mean of five mice in each group (4, 8 , and 20 weeks old), and three mice in nephritic group $4 \mathrm{~A}$, and three in $4 \mathrm{~B}$.

TThe nephritic group is subdivided into two subgroups where group 4A consists of three mice selected because of mild nephritis with only mesangial matrix deposits of chromatin-containing immune complexes, while group 4B consists of three mice with severe nephritis with capillary membrane associated immune complexes.

${ }^{\ddagger}$ Means statistically significant at $P<0.05$ and $\geq$ twofold change in transcription versus age-matched BALB/c control mice.

be that camptothecin-induced apoptosis involves cleavage of preformed inactive caspases, however without activating central apoptosis associated genes as those listed in Table 1-at least not within 6 hours of treatment.

\section{Discussion}

Lupus nephritis may be linked to an unusual exposure of secondary necrotic chromatin fragments in kidneys of individuals producing anti-chromatin antibodies. Without antibodies, exposed chromatin may be non-pathogenic, while antibodies in absence of exposed chromatin may represent a clinical epiphenomenon. The lupus nephritis phenotype may therefore be characterized by glomerular binding of complexes of chromatin fragments and antichromatin antibodies. Data presented here demonstrate that deposition of chromatin-IgG complexes in glomerular capillary membranes may depend on reduced renal Dnase 1 activity and not on increased apoptotic activity in the kidneys. The fact that chromatin fragments possess high affinity for glomerular laminins and collagens explains why they are deposited in the kidneys. ${ }^{3}$

No systematic studies have been performed so far related to lupus nephritis that addressed the question whether there is increased apoptosis or reduced clearance of cells undergoing apoptosis in context of regular renal homeostasis. In the present study we analyzed expression of several key regulators of the apoptotic pathways at different stages of lupus nephritis development in BW mice. The aim was to evaluate their possible involvement in the pathogenesis of the disease. We found no formal evidence for increased number of apoptotic cells in morphologically normal kidneys neither in antidsDNA antibody-negative or -positive BW mice. This suggests that generation of anti-nuclear autoantibodies is not due to over-activation of caspase-mediated apoptotic pathways in the kidneys. This, however, does not exclude the possibility that activation of these pathways takes place in other organs. ${ }^{31}$ In the present study, we detected slight increase in the number of activated caspase 3-positive cells during the late phase of nephritis, ie, during transition from mesangial to membranoproliferative lupus nephritis. Increase of renal TNF- $\alpha$ gene transcription and its receptor in the nephritic BW group did not lead to any changes in the gene transcription of its downstream apoptotic regulators and executors, such as FADD, TRADD, Bcl212, BAX, and caspase 3 and 9. These data suggest that the rate of apoptosis in the BW kidneys is not increased by activity, and accumulation of extracellular chromatin fragments found in nephritic kidneys most likely occurs due to other pathological processes such as reduced Dnase1 gene expression (see below). Interestingly, in tubular lumina structures are observed that were specifically stained by antibodies to activated caspase 3 and 9 and to APAF1. Absence of such structures in tubular lumina in kidneys from BALB/c mice with an antibody-driven experimental proteinuria $(>20 \mathrm{~g} / \mathrm{L})$ is a striking observation that argues against the idea that debris in tubular lumina is a nonspecific result of proteinuria. Presence of apoptotic debris in nephritic BW kidneys therefore indicates that accumulation of apoptotic debris is linked to a lupus nephritis-prone disposition, and not to proteinuria per se. Apoptotic cell debris is released into the tubular lumina during development of severe lupus nephritis. Cylinders and casts observed in urine samples from lupus nephritic kidneys may accordingly consist of debris from apoptotic, possibly tubular epithelial cells.

In this study, we observed mostly activated caspase 3-positive cells in tubuli and in the interstitium, and fewer apoptotic cells in glomeruli. This does not necessarily mean that glomerular cells do not contribute to accumu- 
A
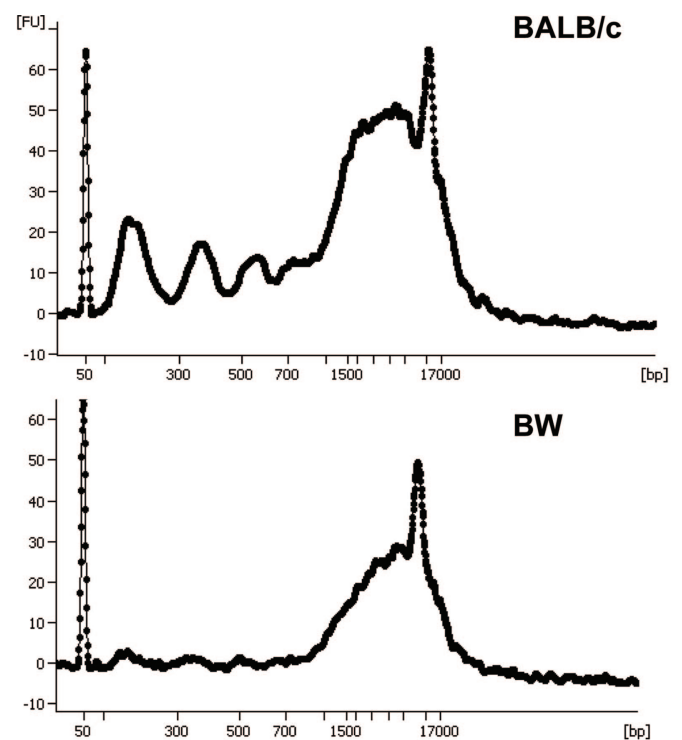

\section{B}

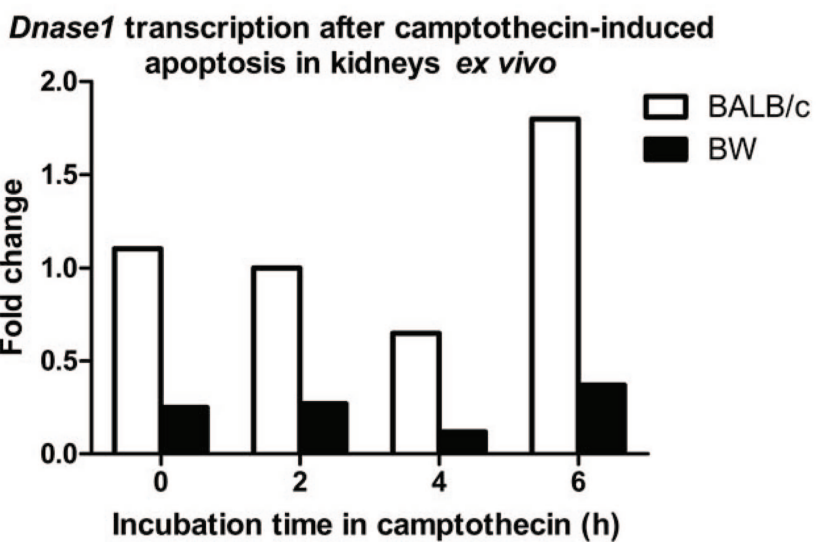

BALB/c

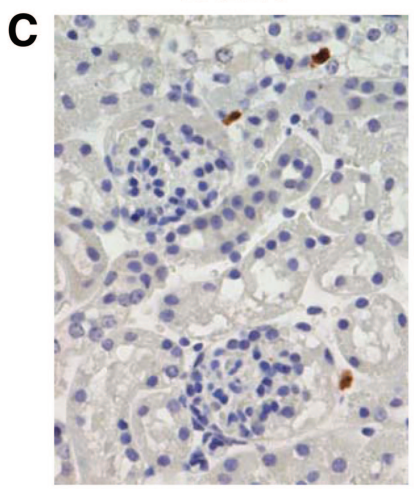

BW

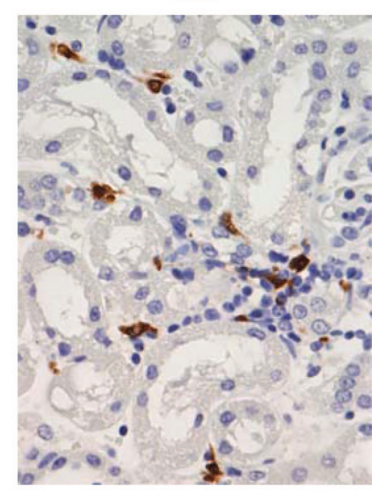

D m

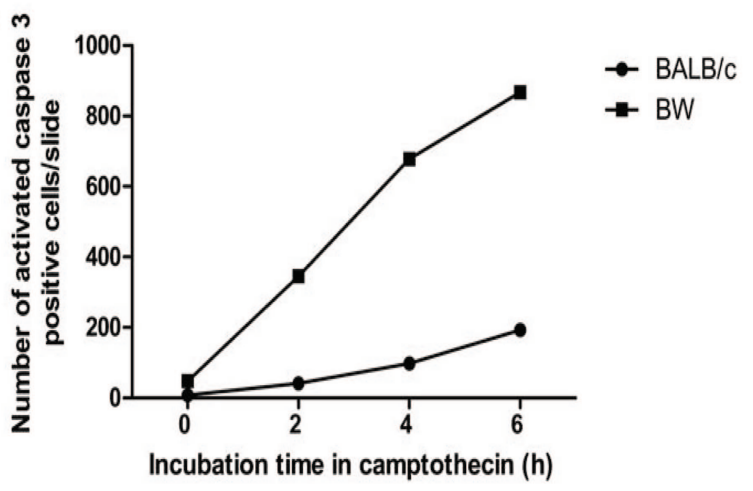

Figure 5. Apoptotic DNA fragmentation, and quantitative analyses of activated caspase 3 positive cells and Dnase1 gene expression after camptothecin-induced apoptosis in isolated nephritic BW kidneys. Camptothecin-induced DNA fragmentation was detected after 6 hours incubation time in kidneys of 26 week old BALB/c mice (A), but not in kidneys of nephritic BW mice (A). Transcription of the Dnase1 gene was stable and very low in nephritic BW kidneys at all time points after apoptosis induction compared with the age-matched BALB/c mice, in which Dnase1 transcription increased at the end of the incubation time in presence of camptothecin (B). This result is consistent with lack of DNA fragmentation in the same kidneys. The number of activated caspase 3 positive cells was increased in nephritic BW kidneys compared with healthy control kidneys after 6 hours incubation with camptothecin (C and $\mathbf{D}$ for immunohistochemistry and number of activated caspase 3 positive cells, respectively). The data in (A) is taken from a larger set of experiments published on the same individual mice as used in this study. $^{27}$

lation of apoptotic debris in glomeruli during development of nephritis. Both we and others have observed glomerular accumulation of activated caspase 3-positive cells during development of severe lupus nephritis (see, ${ }^{5}$ and references therein). These may later be seen as chromatin debris associated with glomerular membranes, while for example, the caspase 3 molecule may be metabolized during transformation of apoptotic cells into secondary necrotic debris due to reduced ability to clear apoptotic cells. Thus absence of activated caspase molecules and retention of chromatin in glomeruli during certain phases of nephritis may not necessarily indicate that apoptotic cells have not been accumulated also in glomeruli. It is also a striking observation that there were only few apoptotic cells in the tubuli and interstitium. Whether tubular apoptotic cells contribute to accumulation of large chromatin fragments in glomeruli remains to be established, but they may do so through, for example, being re-ab- sorbed and then released into the blood stream and brought to glomeruli through circulation.

To investigate whether responsiveness to apoptotic stimuli is compromised in lupus-prone mice, we performed a previously published ex vivo assay of apoptosis induction in kidneys using the topoisomerase I inhibitor camptothecin. ${ }^{27}$ The data demonstrate that activation of caspase 3 in response to artificial apoptosis induction with camptothecin was not reduced-as could be expected from our previous report of the defective nucleosomal DNA fragmentation ${ }^{27}$ _ but rather elevated in the kidneys of lupus-prone mice, particularly in the animals with proteinuria. Thus, mRNA expression of apoptosis related genes, such as pro-caspase 3 may be increased in response to camptothecin as also reported by Floros et $\mathrm{al}^{32}$ In the present experiments the appearance of activated caspase 3-positive cells was not associated with significant changes in mRNA level of central apoptotic 
genes. However, we exposed kidneys for camptothecin for only 6 hours, because longer incubation times would result in necrotic death of cells (unpublished observation). The 6-hour incubation time may not be sufficiently long to up-regulate relevant apoptosis-related mRNA levels. At the same time, transcription of the Dnase 1 gene was low in nephritic, but not in pre-nephritic kidneys before stimulation with camptothecin. Notably, Dnase1 transcription in nephritic kidneys also failed to respond after induction of apoptosis by camptothecin, in contrast to what we observed in the sex- and age-matched BALB/c controls. In the same nephritic BW kidneys, camptothecin failed to induce fragmentation of renal DNA, which is consistent with loss of renal Dnase 1 in these BW kidneys.

Thus, these data confirm low transcription levels of the Dnase1 gene in nephritic kidneys, and inability to increase Dnase1 transcription after experimental induction of apoptosis in nephritic kidneys is a striking observation. No reduction of other nucleases or housekeeping genes was observed after this treatment. ${ }^{27}$ This may be significant since the Dnase1 enzyme is involved in apoptosis. ${ }^{33,34}$ Accordingly, no nucleosomal DNA fragmentation could be observed in the course of camptothecin-induced apoptosis in BW kidneys, ${ }^{27}$ in contrast to effective camptothecin-induced fragmentation of chromatin in kidneys of $B A L B / c$ mice.

No increase in the rate of apoptosis was detected in the kidneys of lupus-prone BW mice either before or on development of nephritis. Activation of key apoptotic effector proteins, like caspase 3 or 9, was not compromised and proceeded normally in these mice, but did not lead to generation of nucleosomal DNA fragments (present study, see also ${ }^{27}$ ). Selective lack of production of the dominant renal nuclease, the Dnase1 enzyme, in the proteinuric kidneys and the absence of its up-regulation in the course of experimentally induced apoptosis seem to be responsible for the observed defect in apoptotic DNA fragmentation. This may conceivably explain deposition of large chromatin fragments in the glomerular capillary membranes and mesangial matrix, although chromatin fragments in complex with IgG may be seen restricted to the mesangial matrix before loss of Dnase 1 enzyme activity. Expression of mRNA for other nucleases that we have tested was not reduced even in nephritic kidneys. ${ }^{27}$

In conclusion, the most significant finding in this study is the lack of up-regulation of key renal apoptosis-related genes including genes that are central signal transductors in different apoptotic pathways during development of lupus nephritis in the BW mice. This indicates that lupus nephritis is not linked to increased apoptotic processes in the kidneys. Rather, reduced clearance of physiologically generated apoptotic cells may lead to transformation of the apoptotic cells into secondary necrotic ones with subsequent exposure and deposition of chromatin fragments in glomerular capillary membranes in complex with anti-chromatin antibodies. The present data indicate that progression of lupus nephritis, or at least the variant that spontaneously develop in (NZBXNZW)F1 and MRLIpr/lpr mice, is linked to reduced clearance of chromatin due to reduced production of the main renal nuclease- the Dnase1 enzyme. In that situation, large chromatin fragments accumulate in the extracellular space, and may bind to, for example, glomerular membranes in complex with IgG anti-chromatin antibodies. This deposition may be the fundamental event that creates the basis for development of full-blown lupus nephritis. Loss of Dnase1 enzyme activity, and not increased apoptosis, may transform mild mesangial lupus nephritis into severe membranoproliferative end-stage organ disease.

\section{Acknowledgments}

We thank Jørgen Benjaminsen and Randi Olsen at the Department of Electron microscopy for excellent technical help. We are thankful to Kristin Fenton for discussions and critical comments throughout the work.

\section{References}

1. Weening JJ, D'Agati VD, Schwartz MM, Seshan SV, Alpers CE, Appel GB, Balow JE, Bruijn JA, Cook T, Ferrario F, Fogo AB, Ginzler EM, Hebert L, Hill G, Hill P, Jennette JC, Kong NC, Lesavre P, Lockshin M, Looi LM, Makino H, Moura LA, Nagata M: The classification of glomerulonephritis in systemic lupus erythematosus revisited. J Am Soc Nephrol 2004, 15:241-250

2. Berden JH, Licht R, van Bruggen MC, Tax WJ: Role of nucleosomes for induction and glomerular binding of autoantibodies in lupus nephritis. Curr Opin Nephrol Hypertens 1999, 8:299-306

3. Mjelle JE, Rekvig OP, Fenton KA: Nucleosomes possess a high affinity for glomerular laminin and collagen IV and bind nephritogenic antibodies in murine lupus-like nephritis. Ann Rheum Dis 2007, 66:1661-1668

4. Mohan C, Adams S, Stanik V, Datta SK: Nucleosome: a major immunogen for pathogenic autoantibody-inducing $T$ cells of lupus. J Exp Med 1993, 177:1367-1381

5. Kalaaji M, Mortensen E, Jorgensen L, Olsen R, Rekvig OP: Nephritogenic lupus antibodies recognize glomerular basement membraneassociated chromatin fragments released from apoptotic intraglomerular cells. Am J Pathol 2006, 168:1779-1792

6. Kalaaji M, Fenton KA, Mortensen ES, Olsen R, Sturfelt G, Alm P, Rekvig OP: Glomerular apoptotic nucleosomes are central target structures for nephritogenic antibodies in human SLE nephritis. Kidney Int 2007, 71:664-672

7. Tax WJ, Kramers C, van Bruggen MC, Berden JH: Apoptosis, nucleosomes, and nephritis in systemic lupus erythematosus. Kidney Int 1995, 48:666-673

8. Kaplan MJ: Apoptosis in systemic lupus erythematosus. Clin Immunol 2004, 112:210-218

9. Mortensen ES, Fenton KA, Rekvig OP: Lupus nephritis: the central role of nucleosomes revealed. Am J Pathol 2008, 172:275-283

10. Casciola-Rosen LA, Anhalt G, Rosen A: Autoantigens targeted in systemic lupus erythematosus are clustered in two populations of surface structures on apoptotic keratinocytes. J Exp Med 1994, 179:1317-1330

11. Dieker JW, van der Vlag J, Berden JH: Deranged removal of apoptotic cells: its role in the genesis of lupus. Nephrol Dial Transplant 2004, 19:282-285

12. Berden JH, Grootscholten C, Jurgen WC, van der Vlag J: Lupus nephritis: a nucleosome waste disposal defect? J Nephrol 2002, 15 Suppl 6:S1-S10

13. Gaipl US, Munoz LE, Grossmayer G, Lauber K, Franz S, Sarter K, Voll RE, Winkler T, Kuhn A, Kalden J, Kern P, Herrmann M: Clearance deficiency and systemic lupus erythematosus (SLE). J Autoimmun 2007, 28:114-121

14. Courtney PA, Williamson K, Crockard AD, Bell AL: Apoptotic lymphocytes in SLE. Lupus 1998, 7:498

15. Emlen W, Niebur J, Kadera R: Accelerated in vitro apoptosis of 
lymphocytes from patients with systemic lupus erythematosus. J Immunol 1994, 152:3685-3692

16. Ren Y, Tang J, Mok MY, Chan AW, Wu A, Lau CS: Increased apoptotic neutrophils and macrophages and impaired macrophage phagocytic clearance of apoptotic neutrophils in systemic lupus erythematosus. Arthritis Rheum 2003, 48:2888-2897

17. Courtney PA, Crockard AD, Williamson K, Irvine AE, Kennedy RJ, Bell AL: Increased apoptotic peripheral blood neutrophils in systemic lupus erythematosus: relations with disease activity, antibodies to double stranded DNA, and neutropenia. Ann Rheum Dis 1999, 58:309-314

18. Makino H, Sugiyama H, Yamasaki Y, Maeshima Y, Wada J, Kashihara $\mathrm{N}$ : Glomerular cell apoptosis in human lupus nephritis. Virchows Arch 2003, 443:67-77

19. Munoz LE, Gaipl US, Franz S, Sheriff A, Voll RE, Kalden JR, Herrmann M: SLE-a disease of clearance deficiency? Rheumatology (Oxford) 2005, 44:1101-1107

20. Gaipl US, Franz S, Voll RE, Sheriff A, Kalden JR, Herrmann M: Defects in the disposal of dying cells lead to autoimmunity. Curr Rheumatol Rep 2004, 6:401-407

21. Kuenkele S, Beyer TD, Voll RE, Kalden JR, Herrmann M: Impaired clearance of apoptotic cells in systemic lupus erythematosus: challenge of T and B cell tolerance. Curr Rheumatol Rep 2003, 5:175-177

22. Nagata S: Apoptosis by death factor. Cell 1997, 88:355-365

23. Hengartner MO: The biochemistry of apoptosis. Nature 2000, 407:770-776

24. Ehrenstein MR, Katz DR, Griffiths MH, Papadaki L, Winkler TH, Kalden JR, Isenberg DA: Human IgG anti-DNA antibodies deposit in kidneys and induce proteinuria in SCID mice. Kidney Int 1995, 48:705-711

25. Kramers C, Hylkema MN, van Bruggen MC, van de Lagemaat $R$, Dijkman HB, Assmann KJ, Smeenk RJ, Berden JH: Anti-nucleosome antibodies complexed to nucleosomal antigens show anti-DNA reac- tivity and bind to rat glomerular basement membrane in vivo. J Clin Invest 1994, 94:568-577

26. Rekvig OP, Moens U, Sundsfjord A, Bredholt G, Osei A, Haaheim H, Traavik T, Arnesen E, Haga HJ: Experimental expression in mice and spontaneous expression in human SLE of polyomavirus T-antigen. A molecular basis for induction of antibodies to DNA and eukaryotic transcription factors. J Clin Invest 1997, 99:2045-2054

27. Zykova SN, Seredkina N, Benjaminsen J, Rekvig OP: Reduced fragmentation of apoptotic chromatin is associated with nephritis in lupusprone (NZB x NZW)F(1) mice. Arthritis Rheum 2008, 58:813-825

28. Jeruc J, Vizjak A, Rozman B, Ferluga D: Immunohistochemical expression of activated caspase-3 as a marker of apoptosis in glomeruli of human lupus nephritis. Am J Kidney Dis 2006, 48:410-418

29. Baima B, Sticherling M: How specific is the TUNEL reaction? An account of a histochemical study on human skin. Am J Dermatopathol 2002, 24:130-134

30. Basnakian AG, Apostolov EO, Yin X, Napirei M, Mannherz HG, Shah SV: Cisplatin nephrotoxicity is mediated by deoxyribonuclease I. J Am Soc Nephrol 2005, 16:697-702

31. Papadaki HA, Boumpas DT, Gibson FM, Jayne DR, Axford JS, Gordon-Smith EC, Marsh JC, Eliopoulos GD: Increased apoptosis of bone marrow $\mathrm{CD} 34(+)$ cells and impaired function of bone marrow stromal cells in patients with systemic lupus erythematosus. $\mathrm{Br} J$ Haematol 2001, 115:167-174

32. Floros KV, Thomadaki H, Florou D, Talieri M, Scorilas A: Alterations in mRNA expression of apoptosis-related genes BCL2. BAX, FAS, caspase-3, and the novel member BCL2L12 after treatment of human leukemic cell line HL60 with the antineoplastic agent etoposide Ann NY Acad Sci 2006, 1090:89-97

33. Eulitz D, Mannherz HG: Inhibition of deoxyribonuclease I by actin is to protect cells from premature cell death. Apoptosis 2007, 12:1511-1521

34. Mannherz HG, Peitsch MC, Zanotti S, Paddenberg R, Polzar B: A new function for an old enzyme: the role of DNase I in apoptosis. Curr Top Microbiol Immunol 1995, 198:161-174 